\title{
The Bystander Effect: A Lens for Understanding Patterns of Participation
}

\author{
James M. Hudson and Amy S. Bruckman \\ College of Computing \\ Georgia Institute of Technology
}

\begin{abstract}
A number of studies have shown that students are often more willing to participate in educational conversations online than in the classroom. However, other studies have shown that online environments have poor student participation Why is this the case? What causes participation to vary from one environment to another? To explore these phenomena, we borrow a concept from social psychology, the bystander effect, which explains why individuals are less likely to help in an emergency if others are present. Although the bystander effect specifically applies to helping behavior in emergency situations, we use this construct as a lens through which to view nonemergency situations such as educational environments. The bystander effect has 4 key components: self-awareness, social cues, blocking mechanisms, and diffuse responsibility. Focusing on these mechanisms can help us more fully characterize participation patterns observed in different educational environments and leverage this knowledge in the design of such systems. We present a case study of two students in both classroom and online French learning environments and show how the psychological mechanisms of the bystander effect help us understand observed behavioral changes.
\end{abstract}

Any dialog-large or small, written or oral, scientific or casual-involves two well-defined roles: speaker and listener. In productive discourse, participants must play each of these roles at some point. For a speaker to speak, there must be an audience; for a discussion to continue, the audience must respond. Authors from many aspects of academia have attempted to define conversation and discussion in many ways, but these two features remain consistent. Ong (1982, p. 176) wrote:

Correspondence and requests for reprints should be sent to James M. Hudson, College of Computing, Georgia Institute of Technology, Atlanta, GA 30332-0280. E-mail: jhudson@cc.gatech.edu 
Human communication, verbal or other ... demands anticipated feedback in order to take place at all. ... In real human communication, the sender has to be not only in the sender position but also in the receiver position before he or she can send anything. To speak, you have to address another or others. People in their right minds do not stray through the woods just talking at random to nobody. Even to talk to yourself you have to pretend that you are two people. ... Human communication is never one-way. Always, it not only calls for response but is shaped in its very form and content by anticipated response.

Discussion necessarily involves both a speaker and a listener. The role of the speaker must also be taken on by one of the listeners after an appropriate interval. Conversation occurs in this continual exchange of the speaker role among those involved.

\section{WHAT IS CONVERSATIONAL PARTICIPATION AND WHY IS IT IMPORTANT?}

Discussion necessarily involves both a speaker and a listener. The role of the speaker must also be taken on by one of the listeners after an appropriate interval. Conversation occurs in this continual exchange of the speaker role among those involved.

Participation in a conversation involves taking the roles of both speaker and listener at some points during the conversation. Unlike engagement, which only requires active mental attention, participation requires that listeners also contribute to the discussion. For example, an individual is engaged by a televised debate without actually participating in that discussion. This is true of all conversations, from short chats between friends to scientific discussions occurring across generations. Regardless of time scale or media, participation in a conversation requires that the individual actively contribute.

Sociocognitive approaches to learning emphasize the importance of participation in activity as part of the learning process. In their work on learning in traditional apprenticeship domains, Lave and Wenger (1991) argued that learning is a process of moving from being an outsider to becoming a full participant in the activities of the community. This occurs through the process of legitimate peripheral participation, where the newcomer begins by performing small, legitimate tasks. Over time, the student gradually takes on more of the roles and activities of a full community member. In doing so, participation in the activities of the community becomes both the learning process and the educational goal.

Most educational settings, however, differ significantly from these communities of practice. Traditional apprenticeship involves informal learning through being in the presence of a domain expert. Typically, learners of all levels populate the apprenticeship environment; younger students learn from both the master and older students. Target apprenticeship skills typically emphasize physical artifacts that are easy to observe, evaluate, and talk about. In a classroom, none of this is true. The 
teacher is usually not a true domain expert (Brown et al., 1993). The biology teacher, for example, is not a biologist nor is he or she expected to be one. Classes are designed so that students of approximately the same developmental level are grouped together (Lave \& Wenger, 1991). Many target skills in school emphasize cognitive tasks that are not easily observed and evaluated (Collins, Brown, \& Newman, 1989).

Nonetheless, many strengths of apprenticeship have found their way into classroom settings through the notion of a community of learners (Rogoff, 1994). As Rogoff explained

Learning is a process of transformation of participation itself. ... How people develop is a function of their transforming roles and understanding in the activities in which they participate. (Rogoff, 1994, p. 209, italics in original)

In a community of learners, learning is a process of students gradually becoming experts in a given domain. Expertise, however, involves students changing the ways that they perform domain activities rather than simply gaining new knowledge. Scardamalia and Bereiter (1991) emphasized that this type of participation is a process of shifting the locus of educational control to the student. Learning is a process of shifting this locus of self-control and self-regulation from a more knowledgeable power figure such as the parent or teacher to an internal form of monitoring and regulation (Wertsch, 1985). Participation in a community of learners marks the individual's gradual assumption of agency.

Participation in discursive activities plays an important role in many learning domains. Although many computer-supported collaborative learning (CSCL) projects have focused on supporting this type of discursive community (e.g., Riel, 1996; Songer, 1996), participation remains a challenge. In fact, low participation in online environments seems common enough that to be referred to as the "dirty little secret" of the CSCL community (Guzdial, 1997b). A number of asynchronous, text-based environments report limited student participation (Davis \& Huttenlocher, 1995; Guzdial, 1997a; Palonen \& Hakkarainen, 2000). In other cases, however, the same tool has strong student participation in one learning domain (Rick, Guzdial, Carroll, Holloway-Attaway, \& Walker, 2002) with little or no participation in other domains (Guzdial et al., 2001).

What factors influence participation in CSCL and other educational environments? How can we make sense of the complex social interaction in these environments? In this article, we argue that the social psychological notion of the bystander effect provides a lens through which to interpret and understand participation patterns in complex social and educational settings. Research in the learning sciences is interdisciplinary, building on work and borrowing methods from anthropology, cognitive science, computer science, education, psychology, sociology, and many other disciplines. This article offers an example of how an area of the social psychological literature that is less well known in the learning 
sciences community - the bystander effect — can help us better understand research problems in the learning sciences.

In the next section, we present an overview of the bystander effect in its original form. Althought the bystander effect specifically describes nonresponse in emergency situations, we argue that it also helps explain nonresponse in other social settings, such as classroom conversations. Then we describe research on foreign language learning environments, where participation is often regarded as a key difficulty. Online foreign language learning environments have frequently improved poor classroom participation rates. We present a case study of one such environment, IRC Français, to explore how the bystander effect helps to explain these participation changes.

\section{THE BYSTANDER EFFECT: A LENS FOR UNDERSTANDING PARTICIPATION}

In 1964, the story surrounding Kitty Genovese's murder was shocking enough to receive national media coverage. As Genovese returned to her New York City apartment one evening, she was followed by a stranger. In a stairwell plainly visible from other apartments, this stranger proceeded to attack her. During the next half hour, thirty-eight of her neighbors heard her screams and witnessed her murder from their windows, but none called the police, ${ }^{1}$ much less intervened (Rosenthal, 1964/1999). It would be nice to believe that this was an isolated incident, but less extreme examples happen every day. Consider, for example, the number of people who never stop to help when driving by someone on the roadside struggling with a flat tire. Although explanations for nonresponse such as apathy, habituation, and fear of reprisal can legitimately be posited in such emergencies, the unifying theme ultimately seems to lie in the social psychological phenomenon of the bystander effect. Essentially, the bystander effect suggests that individuals are less likely to offer assistance in an emergency when other witnesses are around. It's not that people are primarily apathetic or that they fear reprisal; rather, the presence of a group actively inhibits an individual from acting in an emergency situation (Latané \& Darley, 1970). Note that the bystander effect itself is not a psychological mechanism. Rather, it is convenient shorthand to refer to some related mechanisms that will be discussed later.

A number of studies by Latané, Darley, and their students offer evidence for this effect. ${ }^{2}$ For example, one such study examined how people react to ambiguous but potentially dangerous situations (Latané \& Darley, 1968). In this study, the participants were male college students who believed that they were waiting to be interviewed about problems with urban life. While the student was filling out the preliminary forms, the room began to fill with acrid smoke. Participants who waited alone gener-

\footnotetext{
${ }^{1}$ One neighbor eventually called the police after the half-hour incident. Before doing so, however, he called a friend in another town for advice.

${ }^{2}$ These studies are summarized with commentary in Latané \& Darley (1970).
} 
ally reported the smoke calmly almost as soon as they noticed it. When the participants waited with two confederates who were trained not to respond to the smoke, only $10 \%$ reported the problem before the designated 6-min stopping point. Surprisingly, however, when the participants waited with two other naïve participants, response rates were still low. When all three students were completely free to respond, the inaction of one inhibited the action of the other two. Latané and Darley (1968) suggested that the reason this happens is that each individual attempts to determine the danger present in the situation simultaneously. In part, each individual does this by attempting to determine how the others interpret the situation. Each, then, interprets the others' reactions as calm rather than as confusion. Therefore, individual attempts to disambiguate the situation actually serve as social cues that inhibit the behaviors of others.

In another study, Latané and Rodin (1969) examined a situation where there was much less ambiguity. Male college students were recruited to participate in market research relating to board games. After showing the participant to a waiting room, the female interviewer crossed through a curtain to work while the student filled out a preliminary questionnaire. While the participant worked, he heard the sound of a crashing cabinet and the interviewer calling out in pain that her ankle was hurt and that she couldn't move. When participants were alone, they attempted to help nearly $70 \%$ of the time. When participants waited with a passive confederate — one trained not to respond - the response rate dropped to less than $10 \%$. As in the previous study, participants waiting with another naïve participant responded significantly more than with the passive confederate and significantly less than when alone. Even when the students waited with friends, they still showed significant signs of inhibition.

Through these and other studies (e.g., Darley \& Latané, 1968; Latané \& Darley, 1969), Latané and Darley (1970) built a model of the stages of decisions that must be made before bystanders will intervene in an emergency. First, bystanders need to notice the emergency. Bystanders then need to interpret the situation as one in which action is necessary and then further interpret it as one in which they specifically should act. Next, bystanders need to determine what form the action should take. Finally, they must actually act. At any point in this decision tree, the bystander can cycle back to previous decision points; it is not a linear decision process. Also, decisions can become blocked when one stage of the decision tree cannot be decided upon. In these cases, bystanders will often exhibit signs of extreme discomfort over inaction. In addition, delayed response will often lead to inaction altogether. The longer bystanders wait to respond, the less likely they are to ever actually respond.

An individual presented with an emergency or situation requiring assistance is likely to help (Latané, 1970). When other people are present, however, any given individual is significantly less likely to help. The likelihood of the emergency victim receiving help at all decreases as the number of bystanders increases (Latané \& Darley, 1970). Four mechanisms seem to contribute to this phenomenon (Latané \& Darley, 1970): 
- Self-awareness: ${ }^{3}$ The (perceived) presence of an audience to his or her actions inhibits the individual from acting. He or she does not want to appear foolish or inappropriate in front of others.

- Social cues: Individuals actively look to one another for cues about how to behave in the situation. The inaction of others will likely cause the inaction of the individual. These social cues can interact with the other mechanisms to increase the effect. If all individuals are initially inhibited, to the audience all will appear inactive. Every individual will perceive all others as inactive, further inhibiting action.

- Blocking: When multiple bystanders take action, the emergency often can become worse. The action - or perceived or suspected action — of one bystander effectively blocks others from taking action.

- Diffuse responsibility: In a situation where only a small percentage of the bystanders can take action, responsibility is diffuse. Each individual feels he or she has only limited responsibility for the negative consequences of inaction.

Although the interaction between these four mechanisms is complex, separating them like this provides a way to observe significant and salient behavior in both emergency and nonemergency situations. This allows us to ask questions about the interaction of these mechanisms with one another.

Although the bystander effect specifically refers to emergency situations, our research involving electronic learning communities suggests that it can also explain differences between classroom and online behavior. We are not arguing that classrooms experience the bystander effect per se. Classrooms and emergency situations are quite different environments. However, similarities in social behavior in the two situations emerge because both situations are influenced by similar underlying social and psychological phenomena. Similarities and differences in phenomena observed between emergency situations and classrooms are caused by similarities and differences in those underlying phenomena, as we shall explore in detail. The bystander effect is a pattern of social behavior that typically emerges in situations with certain key characteristics. The regularity of behavior across different emergency situations is caused by underlying social and psychological phenomena. It's important not to reify the notion of the bystander effect; it is an observed pattern, not a causal entity. A well-understood pattern is a lens that can help make sense of future observations in situations that are both like and unlike the original situation. From this pattern of social interaction, we can begin asking questions to inform the design of new educational environments.

\footnotetext{
${ }^{3}$ The psychological notion of self-awareness is divided into two types of awareness: public and private (Duval \& Wicklund, 1972). Public self-awareness is an awareness that others (the public) are judging the actions of the individual. Private self-awareness occurs when individuals assess their own performance. In the literature on disinhibition on the Internet, only public self-awareness has been correlated with online behavior (Matheson \& Zanna, 1988). All references in this article to self-awareness only refer to public self-awareness.
} 
In the next section, we examine research on foreign language learning environments because participation issues are often more salient than in other domains. Then, we present a case study from one particular environment, IRC Français. Through this case study, we show how the mechanisms of the bystander effect helps structure our observation.

\section{PARTICIPATION IN LANGUAGE LEARNING ENVIRONMENTS}

In foreign language learning environments, participation has been a prominent area of research. Although considerable research has focused on the appropriate types of discourse in learning a foreign language (e.g., Doughty \& Varela, 1998; Krashen, 1985), other research has focused on how to get students talking in the first place. Given that students learning a foreign language often seem inhibited about speaking the language, this research community has focused on general issues of improving student participation in classroom discourse. Although appropriate types of discourse are often more important in other domains, such as science learning, much can be learned from understanding the causes of inhibition and how structural and pedagogical features of the environment contribute to or alleviate these challenges.

In a series of studies, Guiora (1972) examined why it is often difficult to involve teenage and adult language learners in speaking the language. He posited that inhibition should be particularly relevant in foreign language learning because fear of making mistakes is deeply ingrained. As adults, we often present ourselves to one another through our use of language. We tend to be highly aware of this self-presentation and modify our language according to particular situations (Goffman, 1959). Learning a foreign language, however, involves giving up control over self-presentation. This, in turn, leads to inhibition, which disrupts the language learning process. In experimental studies of this hypothesis, Guiora and his colleagues demonstrated that reduced inhibition led to increased oral proficiency in a foreign language. When students were given moderate amounts of alcohol (Guiora, Beit-Hallahmi, Brannon, Dull, \& Scovel, 1972), valium (Guiora, Acton, Erard, \& Strickland, 1980), or placed under hypnosis (Schumann, Holroyd, Campbell, \& Ward, 1978), they performed better at pronouncing a foreign language while exhibiting insignificant decreases in mental reasoning capabilities. Not surprisingly, however, these techniques have not found their way into the average classroom!

Because mind-altering drugs are clearly unacceptable, researchers have explored other approaches, such as conversations over the Internet. One of the most commonly referenced features of the Internet is the way it reduces inhibition (Joinson, 1998; Spears, Lea, \& Postmes, 2001). In Internet communications literature, inhibition reductions are often termed disinhibition. If inhibition is an educational difficulty and the Internet seems to contribute to disinhibition, it makes sense that interaction on the Internet might offer a positive foreign language learning environment. 
In 1985, synchronous text-based chat environments first found their way into the classroom as a tool for foreign language education. This effort began as a way of helping deaf children learn English through the Electronic Networks for Interaction (ENFI) project (Batson, 1993). Because deaf children learning English experience the language only in its written form, they never have the opportunity to explore playful interaction through the language. To them, English is often a fixed, boring language, and motivation to learn the language is difficult to impart to these students. The ENFI project sought to provide playful, English-based interactions in a forum that could easily include the deaf students. ENFI conversations are both written and synchronous, so deaf students were able to use the medium to actively play with the language. As a result, dramatic improvements in motivation to learn were observed (Bruce, Peyton, \& Batson, 1993). The deaf children seemed to thrive in this type of foreign language learning environment.

With the success of chat for deaf language education, a number of other foreign language educators began to look at the use of synchronous, text-based interactions for other types of language students (e.g., Beauvois, 1992b; Kelm, 1992). Even though students of other languages must contend with speaking in addition to writing, these researchers believed that text-based chat could still play a positive role. Much of this early research focused on explaining the role of text-based chat in language learning environments and pedagogies. The largest body of literature has looked at shifting power and dominance relations between individuals. It is now widely accepted in the foreign language learning literature that chat-based online discussions can have a much more democratic quality, with instructors speaking significantly less than they do in the classroom (e.g., Kern, 1995). Not only are teacher-student interactions often more balanced, but some evidence also suggests that gender equity increases in the online environment (Wang \& Hurst, 1997).

Although relatively little work has been done on the learning outcomes of these foreign language learning environments (Ortega, 1997), a number of these studies have taken closer looks at the affective components of the online interactions. In these synchronous online environments, students exhibit higher levels of attention (Beauvois, 1992b). Students are more honest and candid toward those in a position of authority (Kelm, 1992), and they get to know one another much better online than in the classroom environment (Beauvois, 1997). Language use is more extensive and more advanced online than in the classroom (Kern, 1995). Students tend to speak in the foreign language; code switches into the native language - even among participants who share a common native language - are relatively rare (Beauvois, 1992a; Kelm, 1992; Kern, 1995). Finally, there is some evidence that oral language skills improve through this type of text-based activity (Payne \& Whitney, 2002). Many of these findings mirror the results of studies in online work-related environments (e.g., Sproull \& Kiesler, 1991). The student experience in the online environment seems to be rather different from the experience in the classroom. In none of this research, however, is there a suggestion that the online 
environment should replace the classroom. Rather, online learning and classroom learning appear to play complementary roles in learning a language.

A number of foreign language chat environments have shown high amounts of student participation, but research in other learning domains has offered somewhat different results. Why do these significant changes occur in some cases but not in others? Why do students in some text-based online environments exhibit signs of reduced inhibition? What can we learn from the answers to these questions that can inform pedagogical designs of other educational environments? Although there are certainly a number of causes (Guzdial \& Carroll, 2002), a deeper understanding of inhibition, especially as it relates to learning in online environments, can contribute to our understanding of both student behavior in existing systems and the design of new systems.

\section{THE RESEARCH PLATFORM: IRC FRANÇAIS}

When we began looking into how we might build on this work in 1998, we spoke with a number of teachers about the issues they faced in their daily teaching experiences. Although previous work in online foreign language learning environments offered interesting results, few of these teachers were willing to give up any of their limited face-to-face classroom time. They were willing to experiment with online environments, but not at the expense of face-to-face time. Given that all of the previously designed software for foreign language learning required collocated participation, we felt the need to develop new software and a new pedagogical approach that would allow a chat environment to be used as a supplement to in-class activity. This led to the development of IRC Français (Table 1). See Hudson and Bruckman (2002) for a full description of the design process.

TABLE 1

Classroom Trials Using IRC Français

\begin{tabular}{|c|c|c|c|}
\hline Semester & $\begin{array}{l}\text { Number } \\
\text { of Classes }\end{array}$ & $\begin{array}{l}\text { Number of } \\
\text { Students }\end{array}$ & Brief Description \\
\hline Fall 1998 & 1 & 9 & $\begin{array}{l}\text { Participation was strictly voluntary. Interaction } \\
\text { involved native speakers. Early software prototype. }\end{array}$ \\
\hline Spring 2000 & 6 & 49 & $\begin{array}{l}\text { Complete software rewrite. Participation integrated } \\
\text { into the classroom. Interaction involves only other } \\
\text { students and the host. Researcher observation of } \\
\text { classroom activities. }\end{array}$ \\
\hline Fall 2000 & 4 & 45 & $\begin{array}{l}\text { Periodic researcher observation of classroom activities. } \\
\text { Minor software revisions. }\end{array}$ \\
\hline Spring 2001 & 5 & 72 & Minor software revisions. \\
\hline Fall 2001 & 3 & 76 & Limited researcher involvement. No software revision. \\
\hline
\end{tabular}

Note. Both the IRC Français software and our pedagogical approaches to its use have evolved since the project started in 1998 . 
At its core, IRC Français ${ }^{4}$ is an Internet Relay Chat (IRC) client program. It is a textual discussion space that allows users to interact with one another over the Internet. In this environment, individuals are synchronously located in the same virtual space, even though they may not be physically collocated. Each is able to type a short message (typically only a sentence or two) and have all others see it immediately upon pressing the return key. As new messages arrive, older ones scroll off the top of the screen (see Figure 1).

A number of similar software products (IRC clients) exist, but designing our own software allowed us to tailor the software to the unique needs of foreign language learners (Soloway, Guzdial, \& Hay, 1994). Most similar products present users with vast quantities of information relevant only to expert users. Technical details, however, often cause students to get bogged down with superfluous information (Bruckman, 1997). Also, we added the ability for students to use accented characters easily without remembering cryptic keyboard combinations.

We took advantage of multiple instructors using IRC Français to provide a way for students to interact with those outside of their classroom walls. In a typical semester, four or five teachers representing a couple of universities required their students to participate in $1 \mathrm{hr}$ of online conversation each week. Instructors evaluated these online conversations based primarily on participation, accounting for approximately $10 \%$ of the final grade. Face-to-face participation generally accounted for another $10 \%$ of the final grade. Each teacher scheduled $1 \mathrm{hr}$ per week when they would be online to host a conversation on a given topic. Because students could attend any of these scheduled sessions, they had four or five opportunities per week to take part in a conversation. Most students were able to easily find a time that did not conflict with other events on their personal schedules.

Informal evaluation of this environment through interviews, classroom observation, and log file analysis showed that we replicated many of the behavior patterns that had been observed by researchers using students in collocated environments. In general, the classroom environment seems to follow an initiate-respond-evaluate (IRE) cycle. In this type of cycle, the instructor opens the discussion with a question, a particular student responds to the question, and the instructor evaluates and expands upon the response (Newman, Griffin, \& Cole, 1989). As one student described her classroom

[The teacher] talks most of the time, actually. Literally, I maybe get in two to three sentences in class of me actually speaking. ... It's a bit awkward sometimes because she'll pose these questions. It's supposed to be a free forum for anyone to answer and try to get a discussion started. Maybe we're just not comfortable enough with each other yet to actually do that. So, everyone just

${ }^{4}$ http://www.cc.gatech.edu/elc/irc-francais 




FIGURE 1 The IRC Français interface provides students with a number of affordances specifically designed to support foreign language learning.

kind of sits there and she'll go around the circle prompting you to respond to the question. Everyone takes their seven seconds in the limelight and says something. And that's it.

In the classroom, teachers are often dominant, pivotal figures for discussion even though they make conscious efforts to avoid this type of interaction. Figures 2 and 3 illustrate the classroom interaction patterns for one teacher, Prof. Poulain, ${ }^{5}$ whom we discuss in more detail later. Note that two students, Sara and Christian, will also be discussed later.

In the online environment, many of these patterns reverse. When the teacher poses a question, the majority of the students respond. Then, as the instructor starts typing a response to one student's comments, the students continue to respond to one another. In short, a much more democratic type of interaction develops in the online environment, even with a configuration of students and instructor nearly identical to that in the classroom. Figures 4 and 5 illustrate conversations with

\footnotetext{
${ }^{5}$ All names have been changed.
} 


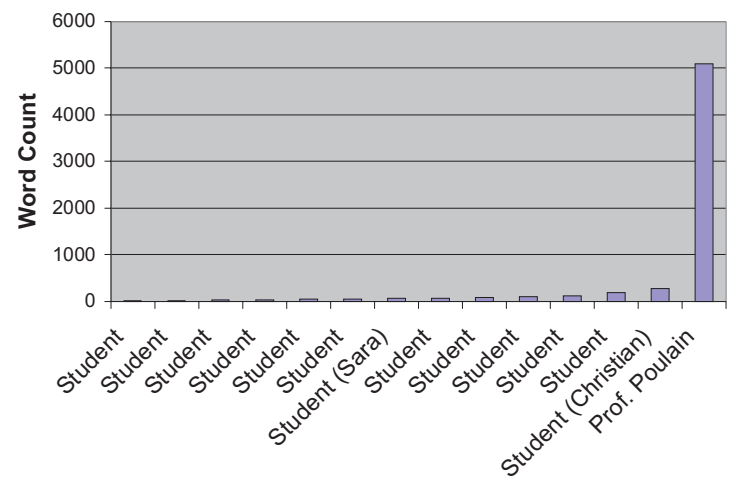

FIGURE 2 Examining word count for a single class session illustrates that Prof. Poulain was the dominant figure in the classroom.

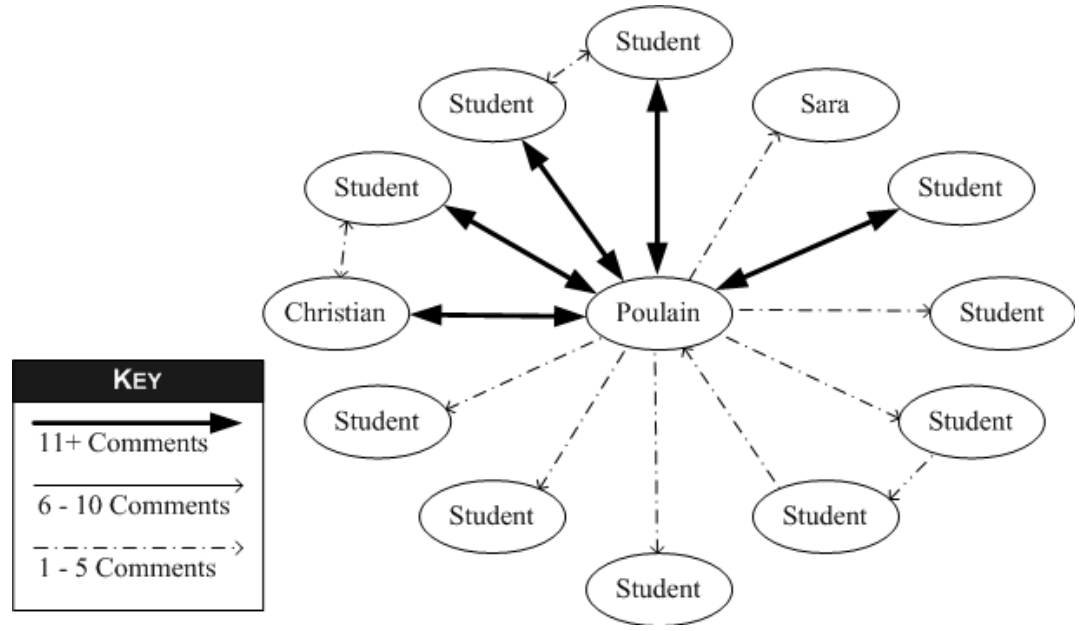

FIGURE 3 A graph of how individuals interact with one another for the same class session shows that Prof. Poulain was the pivotal figure.

Prof. Poulain in the IRC Français environment. Participation differences still exist, but participation is generally higher than in the classroom.

Although there are a number of factors influencing participation when students interact online, we propose that the bystander effect provides a way to understand this social phenomenon. Through this lens, we are able to see new aspects of the environment and make sense of the complexity. 


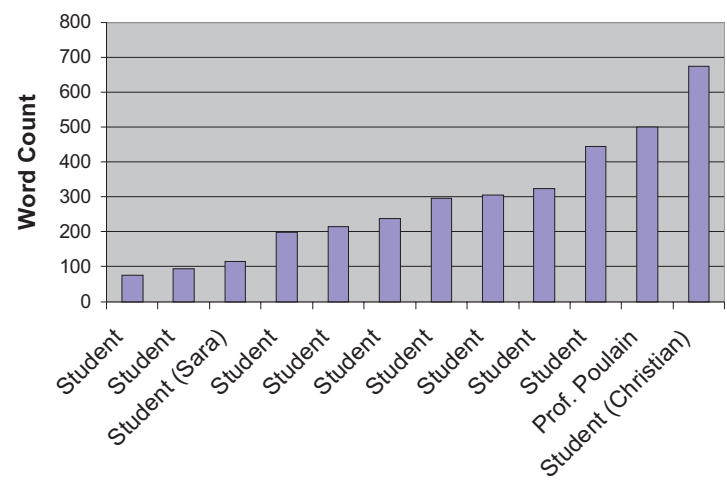

FIGURE 4 In the online environment, Prof. Poulain was a less dominant figure. This figure represents averages across all conversations involving Prof. Poulain.

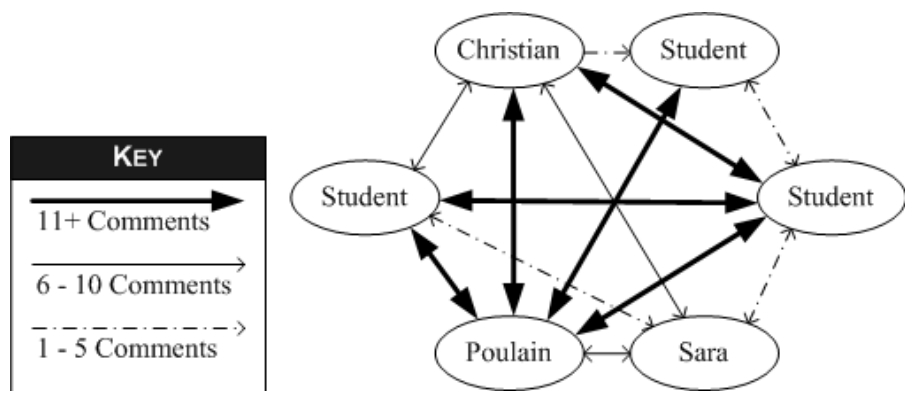

FIGURE 5 The interaction graph for one online session shows that students interact with one another more online.

\section{CASE STUDY: PARTICIPATION IN IRC FRANÇAIS}

Although we have used IRC Français over many semesters in varying ways, this case study focuses on two particular students from one classroom. Christian was a vocal, confident student whose behavior changed little when conversations took place online. Sara, however, was a quiet, shy student who participates in conversa- 
tions more actively in the online environment than in the classroom. Examining these two students illustrates how the bystander effect helps us understand their behavioral changes.

Sara was a shy freshman who took this class in her second semester at Georgia Tech. She described her first reaction to the class as

I don't really talk that much in French class because the first day I came in, I heard everyone else speaking and realized that they had all been to France and they were very good at it.

In a class of 12 students, Sara was 1 of 3 freshmen. She had 21/2 years of French in high school and only one quarter in college. She was intimidated by the others in the room and their variety of experiences with the French language. As she indicated on the introductory survey

Because I am unable to speak very fluently, I dread the conversational portion of learning French.

Christian was the opposite. Whereas Sara was a shy freshman, Christian was a confident senior. Born in Haiti, a French-speaking country, Christian immigrated to the United States with his immediate family at approximately the same time that he began his studies at Georgia Tech. In Haiti, which is a poor country, he was raised by a relatively wealthy family. Having moved to the United States, Christian has a strong desire to be able to share some of his experiences in Haiti with his classmates, whom he views as sheltered:

Ever since I had a French class here, I've wanted to have a sit down with the students and tell them, for me, as in the upper-middle class in Haiti, how hard it was even though you have money. Meaning how worthless money was because it was just the country that was unbearable. I wanted them to ask me questions. I wanted to tell them what it feels like to see dead bodies in the street, or cut up bodies in the street, or have TVs with no censorship showing like burnt body parts. These things are things you never think about when you are in the States.

Although he sometimes seemed slightly arrogant or condescending, this desire to expose the other students to his experiences in Haiti didn't come across that way. Rather, it came across as a need to cope with a deeply personal tragedy through sharing with others. With a smile, he described why he was often more talkative than others in a classroom: 
The more personal [it] get[s], the more you talk. I guess that's why I talk a lot. I take everything personally.

Clearly, the best French speaker in the class, Christian often dominated the discussion.

In the classroom, Prof. Poulain used many common pedagogical practices for increasing student engagement, but only with limited success. He arranged the room in a circle so that all students could see one another. He often used a text-a book chapter, newspaper article, etc. - as the starting point for classroom discussions, so that all students had some foundation from which to participate. He tried to supplement the more academic reading material with interesting personal or cultural stories and anecdotes:

I usually try to challenge them by assuming or stating things that might not necessarily be true that I know will get a reaction. ... [In the classroom, I try to have students] compare what you're learning to what you know and how they can relate.

Many students seemed to actively listen, but few joined the discussion. Sara and Christian represented the extremes seen in the class. In the classroom conversations that we observed, the only time that Sara spoke was when explicitly called upon to read from the text. Periodically, Prof. Poulain would have all students work in pairs to require all students to participate. In these cases, Sara interacted with her partner, but required her interlocutor to present their findings to the class.

Christian, however, was extremely vocal. In fact, often Prof. Poulain would attempt to explicitly ignore him so that other students would have a chance to interact as well. Just as often, Christian would attempt to assist Prof. Poulain when he struggled for the right phrase, or he would introduce obscure French cultural references into the discussion to show off his knowledge. In one particular example, Prof. Poulain had commented on how a particular phrase tended to be a tongue twister for American students. This led into Prof. Poulain providing a common French tongue twister for the class to attempt. Rather than moving on, however, Christian insisted on offering examples that he knew, even through Prof. Poulain's tone and body language strongly suggested that he would rather take the discussion in other directions.

1. Prof. Poulain: Oui, oui. Ça existe, par exemple on a des choses comme, "Ces cypres sont si loin qu'on ne sait si s'en sont." (Yes, yes. They exist, for example, we have things like "Ces cypress sont si loin qu'on ne sait si s'en sont.")

2. (A few students talk at once) 
3. Prof. Poulain: Oui, "les chaussettes de l'archi du chesse..." On dit ca, c'est le terme plus literaire, c'est des alliterations (Yes, "les chaussettes de l'archi du chesse..." We say that, it is a more literary term, it is alliteration.)

4. Christian: "Les poissons sont boissons en poison." (Tongue twister)

5. Prof. Poulain: Oui, des trucs comme ça. (Yes, things like that.)

6. Christian: "Les deux minutes de minuit diminus." (Tongue twister)

7. Prof. Poulain: Ok, pas mal. D'accord on va ecrire quelques-uns pour voir si vous les connaisses. "Ces cypres sont si loin qu'on ne sait si s'en sont." (Ok, not bad. Ok, I'm going to write some to see if you know them. "Ces cypress sont si loin qu'on ne sait si s'en sont.")

Although Christian and Sara represent the extremes of the students in the classroom, few students approached Christian's lack of inhibition. Rather, most waited to be called on before participating. In looking at the classroom, Prof. Poulain was almost always the pivotal figure, as the charts in the previous section illustrate. Nearly all of the students' comments were directed to him. Although Prof. Poulain managed to maintain a dialog with the students for the class period, discussion between students rarely occurred unless Prof. Poulain divided them into small groups for exercises.

When online, however, things were rather different. Consider the following online conversation that occurred relatively early in the semester. This segment took place immediately after Sara entered the chat room several minutes late. Before she entered, the others had been discussing various differences between major world cultures.

1. Prof. Poulain: bienvenu Sara (welcome Sara)

2. Christian: bonjour sara (good day sara)

3. Anne: salut sara (hello sara)

4. Sara: salut tout le monde (hello everyone)

5. Christian: alors nous sommes cinq! (well, now we are five!)

6. Prof. Poulain: Oui, c'est mieux que 4 (Yes, it is better than 4)

7. Christian: lol (lol)

8. Anne: Oui, c'est bon aujourd hui! (Yes, it is good today!)

9. Prof. Poulain: Vous savez des choses sur le travail en France que vous voulez partager? (Do you know some things about work in France that you would like to share?)

10. Christian: hmmm (hmmm)

11. Anne: Je ne sais rien du travail en France ... (I know nothing about work in France...)

12. Christian: combien de temps faut-il pour avoir un travail comme (how much time is necessary to have a job as) 
13. Prof. Poulain: Il ya beaucoup de nouvelles sur la semaine de 35 heures pour tout le monde (There are many news articles about the 35-hour work week for everyone)

14. Christian: avocat, ou medecin (a lawyer or a doctor)

15. Christian: combien de temps a l'ecole (how much time in school)

16. Prof. Poulain: Il faut etudier une dizaine d'annee apres le BAC pour etre medecin, c'est un peu moins long pour etre avocet (One needs to study about ten year after the BAC to be a doctor, it's a little less for a lawyer)

17. Prof. Poulain: d' annees (years)

18. Prof. Poulain: Combien d'heure par semaine travailles-tu Anne? (How many hours per week do you work Anne?)

19. Sara: J'ai une question... Qui veut la semaine de 35 heures? (I have a question... Who wants a 35-hour week?)

20. Anne: Une dizaine après le bac??? (Ten years after the bac???)

21. Christian: il faut beaucoup de temps pour voyager au travail, n'est-ce pas (it takes a lot of time to travel to work, doesn't it)

22. Prof. Poulain: Si on veut se specialiser... moins longtemps pour etre generaliste! (If you want to specialize... less time to be a generalist!)

23. Sara: Je sais qu'aux Etats-Unis, les gens qui travaillent veulent travailler beaucoup d'heures pour gagner plus d'argent... (I know that in the United States, people who work want to work more hours to earn more money...)

24. Prof. Poulain: Ca depend ou on habite, dans la region parisienne oui (It depends on where one lives, in the Paris region yes)

25. Prof. Poulain: la semaine de 35 heures veut dire que personne n'est authorise a travailler + de 35 heures (the 35-hour week argument means that people are not allowed to work more than 35 hours)

26. Prof. Poulain: Pour l'instant, il y a la semaine de 40 heures dans beaucoup d'endroits (Right now, there is a 40-hour week for most places)

27. Christian: comment dit-on "salary" (how does one say "salary")

28. Christian: des appointements? ("des appointements"?)

29. Prof. Poulain: salary is le salaire - Est-ce que vous pensez qu'on devrait limiter le nombre d'heures de travail? (salary is "le salaire"-Do you think we should limit the number of work hours?)

30. Prof. Poulain: appointment ou desappointment? (salary or disappointment?)

31. Christian: je ne sais pas, mais c'est bon pour les gens qui gagne un salaire moins de travail et le même salaire? (I don't know, but it's good for people who earn a salary - less work and the same salary?)

32. Christian: gagnent (money)

33. Sara: Je pense que c'est le choix d'individuel combien d'heures il travail... (I think it is the individual's choice how many hours he works...)

34. Prof. Poulain: Les travailleurs veulent pouvoir travailler + parfois, les entreprises doivent embaucher + de personnes aussi (to hire) (The workers want to 
be able to work more sometimes, the businesses must hire more people as well (to hire))

35. Sara: Mais si on veut un bon job avec un grand salaire, il doit travailler beaucoup d'heures (But if one wants a good job with a large salary, he must work a lot of hours)

36. Prof. Poulain: C'est vrai le choix de l'individu n'est pas toujours le choix que fait l'etat ou le pays! (It's true that the individual's choice is not always the choice that makes the state or the country!)

37. Christian: pas si on ne peut travailler que 35 pour semaine (not if one can work only 35 hours per week)

38. Prof. Poulain: Bien sur les CEO ne sont pas inclus dans la semaines de 35 heures, il ne sont pas paye a l'heure mais au mois! (Of course, the CEOs are not included in the 35-hour week, they are not paid by the hour, but by the month!)

39. Christian: oh (oh)

40. Christian: je vois (I see)

Notice a number of interesting things that happened in this segment. First, the greetings did not resemble the typical greetings in a classroom. Should a student arrive late in a small class, it's common to hear the instructor greet the student, but it is uncommon to hear the others greet the student. It is equally uncommon for the student to verbally respond. Arriving late is more socially acceptable online than in a traditional classroom. Face to face, a late arrival is disruptive. Online, not only can the classroom conversation proceed uninterrupted, but teacher and classmates can also greet the student individually. This small detail contributes to creating a warm, welcoming atmosphere. We will discuss this type of conversational tangent in further detail in the section on blocking.

Next, Prof. Poulain introduced the concept of the work week, particularly in France. After waiting a few minutes to determine what was going on in the environment, Sara jumped in with a question, "J'ai une question... Qui veut la semaine de 35 heures? (I have a question... Who wants a 35-hour week?)" It's interesting to note Sara actively participating in the conversation. This is radically different from her behavior in the classroom. Not only was she actively participating, she was also explicitly questioning the assumptions of the professor's previous statement. When in the classroom, she was the shy student who hid away. In the online environment, she was an active interlocutor who (respectfully) engaged the professor as peer.

The final interesting thing to notice in this excerpt is that the conversation was much more balanced than discussions in the classroom. Even though Prof. Poulain was still a significant figure, his interaction was much more equivalent to the participation of the others. Not only did he avoid monopolizing the dialog with longer soliloquies, but other students also participated more. Something about moving to the online environment seems to cause the conversation to have different proper- 
ties than it had in the classroom. However, it is difficult to access underlying psychological mechanisms behind these changes through observing behavior and interaction in naturalistic environments. Inhibition in social contexts is a complex phenomenon.

\section{DISCUSSION}

In this case study, behavioral changes clearly occur when discussions move from the classroom to the online environment. Why do these particular changes happen? Why wasn't Christian affected in the same way as Sara? Are these changes doing anything to improve the learning experience? In this section, we explore evidence for learning in these online discussions before turning our attention to the underlying psychological mechanisms.

\section{Learning}

Before exploring the mechanisms behind these behavioral changes, we need to examine whether there is evidence that these changes are educationally beneficial. Although we did not conduct formal evaluations of learning, student comments suggest that they did learn through the online conversations. For example, Sara's discussion of her learning through IRC Français reflected comments of many of the other students interviewed:

If I ever go to France, I think that through this [experience on IRC Français], I could carry on a good conversation with someone and feel comfortable with what I know and what I'm saying. ... I think a lot of it was review for me. I had seen everything before. It was just a matter of putting it together. We had not done a lot of that because most of my classes were standard textbook and you didn't really have to think on the spot. So, I think a lot of what I learned was putting things together and having it make sense.

In her previous language learning experience, Sara was exposed to a number of concepts that are necessary for speaking a foreign language. The textbooks that provided the foundation for these courses, however, tended to treat each concept as a separate unit. Like Chi's novice physicists who structured problems in fragmentary ways (Chi, Feltovich, \& Glaser, 1981), Sara's knowledge of the French language at the beginning of class also was largely fragmented into a variety of "problem types" or grammatical structures. The conversational practice that she experienced in IRC Français gave her opportunities to begin integrating this knowledge in a meaningful and flexible way. 
The conversations on IRC Français also gave Sara the opportunity to begin developing more fluent recall:

It's like once you pick up on it and get used to it — at first, I was really, really bad trying to keep up and trying to think of what I was going to say, but towards the end, as I said, I was thinking in French and I didn't have to think in English and translate into French. I think that was a great help and I do believe that I'm going to remember a lot of that portion of it-like just having the words and phrases click in my mind. I think that's going to be the most important part rather than remembering specific words or specific phrases.

At other times in the interview, Sara spoke about the interactive nature of the online discussions helping her learn to play with the French language to get out of binds where she did not know the exact words to convey her thoughts. She spoke of learning to rephrase her thoughts to convey her meaning, even if she did not know the exact words. In other words, she learned how to adapt the vocabulary and grammar to suit new situations.

The strongest critique of this type of online environment, however, is that it doesn't offer much time or support for reflection, an important component of learning (e.g., Kolodner, 1997; Schön, 1987). As we discuss later, the lack of blocking allows for some greater reflection as students compose their comments, but the environment alone seems to offer limited further reflection. In a rapid, synchronous conversation, the student who takes time to reflect conscientiously on various statements will be quickly left behind. Not only does the medium itself discourage reflection, but reduced inhibition or self-awareness also has been shown to correlate with reduced reflection (Greenberg \& Pyszczynski, 1986). Reflection, however, should not necessarily occur at the time that an activity is carried out. Rather, it can be appropriately conducted after the fact. Thus, although text does rapidly scroll off the screen in a chat environment, saving the text for later reflection poses no challenge.

Recognizing the problems of reflection, one teacher using IRC Français regularly with her classes specifically used the transcripts in the classroom as an anchor for further conversations. After her class met online, she reviewed the transcripts to determine common errors. During the next class session, she based grammatical lessons on the common errors she identified. As homework, she expected her students to go through their own transcripts and correct a small handful of their own errors. In this way, she was able to get feedback regarding her students' progress and to encourage students to reflect over their own mistakes and those of their peers. At the same time, however, students never had to correct all of their mistakes. She reports that her students responded enthusiastically to this type of learning activity. 
Because we have reason to believe that this type of online environment contributes to foreign language learning, understanding the behavioral changes observed may help us better understand learning in other online environments. In the next section, we use the features of the bystander effect—-self-awareness, social cues, blocking, and diffuse responsibility — to structure our approach to this case study.

\section{Self-Awareness}

Changes in self-awareness contribute to the behavioral differences seen between the classroom and online environments. Recall that self-awareness is an individual's conscious awareness of others making judgments about that individual. It says nothing about whether or not others actually make judgments but rather refers to the perception of the individual. A person with a high level of self-awareness is highly conscious of others judging him or her regardless of whether anyone is actually doing so. Self-awareness, however, does not directly influence how well students perform in a given environment; rather, the influence of self-awareness on performance is moderated by the level of confidence with which a student enters the situation. Zajonc (1965) found that increased self-awareness helped highly confident students perform better, whereas it lowered the performance of low-confidence students. Likewise, lowered self-awareness helped improve the performance of low-confidence students but degraded the performance of high-confidence students. With Sara and Christian, we see this relationship between self-awareness (moderated by confidence) and conversational participation.

The differing confidence between Sara and Christian can be seen clearly in how they interact in the classroom. For example, Christian often responded to Prof. Poulain's general questions without raising his hand. He was comfortable interacting with others in French because his language abilities were significantly greater than the other students in the class. Growing up in Haiti, he had significant exposure to the language and probably belonged in a more advanced class. He was rightfully confident that his abilities were better than the other students in the class. He described himself as "fluent in French" and often talked about enjoying "being able to help [the other students] improve their skills."

Sara, however, did not have nearly the same abilities or confidence as Christian. Her abilities were much more comparable to the others in the classroom, and she had not had the experience of being immersed in a French-speaking culture. She judged the other students to be better at speaking the language, which caused her to participate less. Sara lacked confidence in her language abilities in part because she judged them to be worse than the other students in the class.

Although Sara and Christian had different levels of confidence in the classroom, they both experienced increased self-awareness. Christian expressed the 
general awareness that students have of an audience when they are in the classroom:

In class when you are being asked a question and you have to say something, you become very hesitant. And then you're wondering whether you're saying the right thing or not, whether the teacher is going to say something. ... I've noticed that a lot of people in my class lack the confidence. They don't believe that their French is actually good.

In the classroom, students are strongly aware of an audience making judgments of their actions; self-awareness increases in the classroom. Christian continued to contrast the classroom with the online environment:

[Online] they feel they are able to express their opinion or say something without really feeling the burden of eyes around them or feeling that they said something that wasn't too correct.

In the online environment, students do not feel the same sense of a judging audience; self-awareness is significantly lower online.

According to Zajonc's (1965) social facilitation theory, we should expect that the high-confidence students perform better with higher self-awareness and that the low-confidence students perform better with lower self-awareness. In the case of learning conversational skills in a foreign language, performance is largely intertwined with participation. Therefore, we should expect to see participation relate to confidence and self-awareness. This is certainly the case with Sara's performance in these environments. As discussed earlier, she said almost nothing in the classroom, but took a more active role in conversations online:

I liked it. I spoke much more.... I got to know my French class really well at the end, and I started thinking in French.

She spoke of how being online helped her begin to develop the confidence to speak in face-to-face settings:

I also found that I knew more French than I gave myself credit for. ... I'm not scared to speak French now. When I see some of the people outside of class, I'll say something in French to them. The friendships that were built through the chat room have given me the confidence to speak more.

Reduced self-awareness in the online environment interacted with Sara's low confidence to help her participate more. In doing so, she found that her abilities were good enough to give her increased confidence to participate more in face-to-face 
environments where self-awareness is significantly greater. In the case of Christian, we see relatively little change in his participation patterns. He spoke a lot in the classroom, and he spoke a lot online.

Christian was generally confident in his language abilities and performed well no matter which environment he was in. Sara, however, had little confidence, but performed better in the online environment than she did in the classroom. This participation change largely stems from a reduction in self-awareness in the online environment. Why is self-awareness reduced online? As we discuss in the next sections, part of it comes from the absence of certain social cues and from non-blocking interaction.

\section{Social Cues}

Some of the behavioral differences observed in the online environment stem from the reduced social cues available, but not in the ways that we might expect. Previous literature on the reduction of social cues in online environments suggests that people are generally less inhibited online because they do not have to endure the disapproving looks of others when they violate social norms (e.g., Weisband, 1992). Comments by Sara and Christian, however, indicate that this is less of a concern than we would expect. Rather, students seem to worry that others can pick up on mistakes more easily in the classroom because they can see the extra social cues (stuttering, long pauses, etc.) that highlight the mistake.

As Christian said, students can interact online "without really feeling the burden of eyes around them." Sara, however, pointed out that the fear of others staring at her does not relate to judgmental looks or any other social cues from the other students. Rather, she was aware that she had small signs, such as a player's tell in a game of poker, that gave away when she had made a mistake:

If I mess up in class, I kind of look around or I pause. No one can notice that online. I don't stutter online if I mess up on a word. I don't have long pauses online.... I didn't really talk [in the classroom] because I didn't want them to hear me mess up, but on the French chat room, it was easier to talk because I had my French-English dictionary right there and I could pick up on what other people were saying easier.

Sara was concerned that others in the classroom could see cues-stuttering, pausing, consulting the dictionary - which indicated that she had made a mistake. Talking online allowed Sara to have a space where her tells were not so visible. Although this stems from a reduction in social cues, it is interesting to note that it has to do with the social cues of the individual making mistakes rather than those of the others observing that individual. 


\section{Blocking}

In most face-to-face settings such as the classroom, blocking plays a prominent role. In polite conversation, only one person can speak at once. If one person has the floor, all others are effectively blocked from actively participating. When conversations take place online, however, this type of blocking is removed (Cherny, 1999). If one person is typing or composing a response, all others are also free to do so. One person's participation cannot block another from participating. Because of the nature of the medium, students interacting on IRC Français experience significantly less blocking than they do in the classroom. This contributes to the behavioral changes in two ways: It provides students with a space to reflect on their comments before making them public, and it actively hinders the initiate-respond-evaluate (IRE) cycle from forming.

When students using IRC Français want to add a comment to the conversation, they must first type out the comment, and then press "Enter." Seeing the comment in completed, written form allows students a space in which to reflect on their comment and make corrections before making it publicly available. Sara commented on how this contributed to helping her feel more comfortable speaking in the online environment: "I don't have long pauses online because they can't see that I'm in the middle of typing something. That just made me feel more comfortable." Many other students echoed this theme that the online environment gave them more time to think about their answers than the classroom, but that the time was limited by conversational norms of continuity.

Although the time to think and reflect was important for the students' comfort, the lack of blocking played another role in altering the conversational norms. The lack of blocking meant that it was difficult for anyone to become a pivotal figure online. Because the lack of blocking essentially allowed multiple people to compose messages simultaneously, it was impossible for the instructor or anyone else to control the conversational floor. In the classroom, for example, Prof. Poulain often ignored Christian's raised hand because he was blocking the other students from participating. In the online environment, however, there is no evidence that Prof. Poulain treated Christian's input any differently than he did that of the other students. Christian was not able to block others during the discussions on IRC Français. Likewise, Prof. Poulain could not unintentionally block the students from participating. Therefore, when he was responding to someone's comment online, the discussion continued, effectively prohibiting the initiate-respond-evaluate (IRE) cycle from forming.

These changes in conversational structure allow an interesting pattern of dynamic grouping. In a conversation involving several individuals, small group conversations easily form and rejoin in ways that would be impossible in a classroom setting. In the classroom, all individuals must engage in the same conversation because only one person can talk at any given time. If a subset of the class 
wanted to follow up on a thread of conversation while the rest of the class continued on a different thread, they would need to physically separate and form a small group over in the corner. Of course, this is frowned upon without the instructor's explicit permission! Online, however, multiple conversations can occur simultaneously in the same chat room. Sara described one specific example from her experiences:

[This one time], me, Andrew, and Melissa [the other freshmen] split up and we were talking about different phrases in French and how they related to slang in American - in English - and the other people were talking about French music we had in class. I think our conversation stemmed off of that because of one of the lines in one of the songs. In the end, we rejoined, but for a while, we split off. It was good because it kept everyone involved. Everyone was talking to at least someone. They were on related subjects; we just went off on a tangent. It worked out really well, though.

In the online environment, new conversations can seamlessly spawn, but they can also easily reintegrate because members of both smaller conversations remain aware of the other group's discussion. The interleaving of comments in the online environment allows for monitoring of peripheral conversations with reduced cognitive resources (compared with monitoring another small group discussion in a face-to-face, classroom setting).

\section{Diffuse Responsibility}

The final aspect of the bystander effect, diffuse responsibility, plays an important but unchanging role in both the online and classroom environments. Although both environments exhibit evidence of diffuse responsibility, this does not help explain the behavioral differences observed. In the classroom, when Prof. Poulain asked a question, it was unclear who should respond. As a result, often no one responded until Prof. Poulain called on a specific individual. As the primary exception to this rule, recall Christian's description of why he talked in class, "I guess that's why I talk a lot. I take everything personally." Christian was not constrained to the same type of diffuse responsibility because his personality naturally assumed responsibility for answering Prof. Poulain's questions.

In the interaction on IRC Français, there is no reason to expect that diffusion of responsibility should be different nor is there any evidence that it is. Nothing about Prof. Poulain's questions in the online environment suggests a different responsibility structure than in the classroom. IRC Français allows all users to know how many others are involved in the conversation. This means that students have the same indication of others available to answer the teacher's questions. We have rea- 
son to believe that diffuse responsibility works the same in both of these environments. Therefore, the behavioral changes that we have observed indicate that the other aspects of the bystander effect play a much stronger role in this particular case than diffuse responsibility.

\section{ALTERNATIVE INTERPRETATIONS}

In using the bystander effect as a lens for explaining the causes of participation patterns in various educational environments, we have argued that students become more or less inhibited as a result of a complex interaction between several structural features of the educational setting. Pedagogy and the sociotechnical infrastructure influence the level of fear and inhibition that students face in speaking. Through the mechanisms of the bystander effect, we have suggested a way of breaking down these complex interactions. However, there are other potential explanations for the changing communication patterns.

One alternative interpretation holds that fear of making mistakes is generally reduced in the online environment. This occurs through both the methods we described previously (social cues, self-awareness, social facilitation) and other methods found in the social psychology literature, such as social conformity (Asch, 1956) and cognitive dissonance (Festinger, 1957). Reduced fears occur through a number of mechanisms that play a primary role in participation patterns observed.

Another explanation holds that the unique affordances of working in a textual medium allow for greater disinhibition in online environments. According to this perspective, students feel more comfortable online because they are able to take time to check their grammar or spelling before making a public statement. This explanation incorporates the benefits of removing blocking, but suggests that the other primary mechanisms at play are in giving students the ability to better control self-presentation.

In addition to these, there may be a number of other alternative explanations. We note, however, that these three explanations - the bystander effect, fear reduction, and affordances of text - are not mutually exclusive. Different aspects of these explanations may be more important in some environments and not in others. More research is needed into the mechanisms underlying participation patterns so that we may begin distinguishing among these various alternative explanations.

\section{FUTURE WORK}

To explain the communication patterns we observed using IRC Français, we borrowed the notion of the bystander effect as an analytical tool. Doing so, however, 
raises a number of interesting research questions. How well does this type analysis generalize to other domains, to other learning environments, and to other Internet technologies? Can the mechanisms of the bystander effect be used as a predictive tool in the design of new online environments? Are the four components of the bystander effect independent psychological mechanisms or are they an integral whole that is greater than the sum of the parts? Our current research project-using a CSCL environment to enhance professional ethics education - aims to begin answering these questions through using the mechanisms of the bystander effect (and other education theory) to develop a new learning environment.

In designing this new environment, we are explicitly building on the mechanisms described in the bystander effect. Text discussions are designed to reduce self-awareness and negative social cues. Specific technological and pedagogical decisions seek to reduce opportunities for one student to block another. We also explicitly attempt to design ways to increase individual responsibility. Because the bystander effect is built on social psychological data, we believe that this approach can be used to design new environments favoring high participation among students. Whether this approach will prove beneficial, however, remains an empirical question.

\section{CONCLUSION: UNDERSTANDING TECHNOLOGICALLY MEDIATED CHANGES IN PARTICIPATION PATTERNS}

This is what I do not like. When we talk on the computer, everyone speaks together, but when we are in class, no one says anything. It is like we become strangers again if we are not protected by the computer. (C'est ce que je n'aime pas. Quand on parle sur l'ordinateur, tout le monde bavard ensemble, mais quand nous sommes en classe, personne ne dit rien. C'est comme on devient des etrangeres encore si on n'est pas protege par l'ordinateur.) (Student comment on IRC Français)

In foreign language learning, moving a conversation from the classroom to an online chat environment changes participation patterns (Beauvois, 1992a, 1992b, 1994/1995, 1997; Beauvois \& Eledge, 1995/1996; Bruce et al., 1993; Hudson \& Bruckman, 2002; Kelm, 1992; Kern, 1995). Students feel "protected by the computer." They are more willing to speak and claim agency over the direction of discussion. In this particular domain, this type of online environment helps in realizing a community of learners.

Research from other CSCL domains, however, has indicated that these observed changes do not necessarily occur in other environments (Davis \& Huttenlocher, 1995; Guzdial, 1997a; Guzdial et al., 2001; Guzdial \& Carroll, 2002; Palonen \& Hakkarainen, 2000; Rick et al., 2002). Using the bystander effect 
offers some insights into why researchers studying these environments have observed differing participation patterns.

Borrowing the notion of the bystander effect from social psychology provides us with a new way for examining participation patterns in educational settings. In particular, it suggests four important sets of questions to ask in designing a new learning environment:

1. Self-Awareness: How much self-awareness will be promoted in the new environment? Because self-awareness interacts with confidence to affect performance, how will different students perform? Is the level of self-awareness appropriate for the anticipated level of confidence?

2. Social Cues: What are the social cues available in the environment? Are they likely to generate a positive feedback loop (encouraging discussion) or a negative feedback loop (discouraging discussion)? If a positive feedback loop occurs, are there features in the environment to ensure educationally productive discussions?

3. Blocking: Are there ways for students to block one another from participating in the environment? Can students participate in parallel or must all students pause while one participates? Will one student's answer to a question discourage others from also commenting?

4. Diffuse Responsibility: How are notions of responsibility and accountability conveyed to the students in the environment?

The four mechanisms involved in the bystander effect - self-awareness, social cues, blocking, and diffuse responsibility — can help us to understand observed behavioral patterns and to leverage this knowledge in the design of new systems. Not all of these mechanisms are relevant to all social settings; they simply describe common patterns of behavior. The bystander effect provides a new lens for observing these patterns that can help us understand complex social interaction. However, further research is needed to understand the complex relationships among these four mechanisms and different learning environments.

\section{ACKNOWLEDGMENTS}

We are especially grateful to Mark Guzdial, Marlene Scardamalia, Janet Kolodner, and the anonymous reviewers for their feedback on this article. We also thank Jochen Rick, Jason Elliott, and the members of the Electronic Learning Communities (http://www.cc.gatech.edu/elc) research group for their help. We thank IBM for sponsoring this research through the IBM Research Fellowship program. Special thanks to Wendy Kellogg and Tom Erickson. Thanks to the NSF, Microsoft, Intel, and Ricoh for sponsoring research in the Electronic Learning Communities research group. 


\section{REFERENCES}

Asch, S. (1956). Opinions and Social Pressure. Scientific American, 193(5), 31-35.

Batson, T. (1993). The origins of ENFI. In B. Bruce, J. K. Peyton, \& T. Batson (Eds.), Network-based classrooms: Promises and realities (pp. 87-112). Cambridge, England: Cambridge University Press.

Beauvois, M. H. (1992a). Computer-assisted classroom discussion in French using networked computers. Unpublished doctoral dissertation, University of Texas at Austin.

Beauvois, M. H. (1992b). Computer-assisted classroom discussion in the foreign language classroom: Conversation in slow motion. Foreign Language Annals, 25(5), 455-464.

Beauvois, M. H. (1994/1995). E-talk: Attitudes and motivation in computer-assisted classroom discussion. Computers and the Humanities, 28(3), 177-190.

Beauvois, M. H. (1997). Computer-mediated communication (CMC): Technology for improving speaking and writing. In M. D. Bush \& R. M. Terry (Eds.), Technology-enhanced language learning (pp. 165-184). Lincolnwood, IL: National Textbook.

Beauvois, M. H., \& Eledge, J. (1995/1996). Personality types and megabytes: Student attitudes toward computer mediated communication (CMC) in the language classroom. CALICO Journal, 13(2\&3), $27-45$.

Brown, A. L., Ash, D., Rutherford, M., Nakagawa, K., Gordon, A., \& Campione, J. C. (1993). Distributed expertise in the classroom. In G. Salomon (Ed.), Distributed cognitions: Psychological and educational considerations (pp. 188-228). New York: Cambridge University Press.

Bruce, B. C., Peyton, J. K., \& Batson, T. (Eds.). (1993). Network-based classrooms: Promises and realities. New York: Cambridge University Press.

Bruckman, A. (1997). MOOSE crossing: Construction, community, and learning in a networked virtual world for kids. Unpublished doctoral dissertation, Massachusetts Institute of Technology, Cambridge, MA.

Cherny, L. (1999). Conversation and community: Chat in a virtual world. Stanford, CA: CSLI Publications.

Chi, M. T. H., Feltovich, P. J., \& Glaser, R. (1981). Categorization and representation of physics problems by experts and novices. Cognitive Science, 5(2), 121-152.

Collins, A., Brown, J. S., \& Newman, S. E. (1989). Cognitive apprenticeship: Teaching the craft of reading, writing, and mathematics. In L. B. Resnick (Ed.), Knowing, learning, and instruction: Essays in honor of Robert Glaser (pp. 453-494). Hillsdale, NJ: Lawrence Erlbaum Associates, Inc.

Darley, J. M., \& Latané, B. (1968). Bystander intervention in emergencies: Diffusion of responsibility. Journal of Personality and Social Psychology, 8(4), 377-383.

Davis, J. R., \& Huttenlocher, D. P. (1995). Shared annotation for cooperative learning, Proceedings of Computer Supported Collaborative Learning (CSCL) 1995 (pp. 84-88). Bloomington, IN: Lawrence Erlbaum Associates, Inc.

Doughty, C., \& Varela, E. (1998). Communicative focus on form. In C. Doughty \& J. Williams (Eds.), Focus on form in classroom second language acquisition (pp. 114-138). New York: Cambridge University Press.

Duval, S., \& Wicklund, R. A. (1972). A theory of objective self awareness. New York: Academic Press. Festinger, L. (1957). A theory of cognitive dissonance. Stanford, CA: Stanford University Press.

Goffman, E. (1959). The presentation of self in everyday life. New York: Doubleday.

Greenberg, J., \& Pyszczynski, T. (1986). Persisent high self-focus after failure and low self-focus after success: The depressive self-focusing style. Journal of Personality and Social Psychology, 50(5), $1039-1044$.

Guiora, A. Z. (1972). Construct validity and transpositional research: Toward an empirical study of psychoanalytic concepts. Comprehensive Psychiatry, 13(2), 139-150.

Guiora, A. Z., Acton, W. R., Erard, R., \& Strickland, F. W. (1980). The effects of benzodiazepine (Valium) on permeability of language ego boundaries. Language Learning, 30(2), 351-363. 
Guiora, A. Z., Beit-Hallahmi, B., Brannon, R. C. L., Dull, C. Y., \& Scovel, T. (1972). The effects of experimentally induced changes in ego states on pronunciation ability in a second language: An exploratory study. Comprehensive Psychiatry, 13(5), 421-428.

Guzdial, M. (1997a). Information ecology of collaborations in educational settings: Influence of tool, Proceedings of Computer Supported Collaborative Learning (CSCL) 1997 (pp. 83-91). Toronto, Canada: Lawrence Erlbaum Associates, Inc.

Guzdial, M. (1997b). Information ecology of collaborations in educational settings: Influence of tool. Computer Supported Collaborative Learning (CSCL) Conference talk, Toronto, Canada.

Guzdial, M., \& Carroll, K. (2002). Exploring the lack of dialog in computer-supported collaborative learning, Proceedings of Computer-Supported Collaborative Learning (CSCL) 2002 (pp. 418-424). Boulder, CO: Lawrence Erlbaum Associates, Inc.

Guzdial, M., Ludovice, P., Realff, M., Morley, T., Carroll, K., \& Ladak, A. (2001). The challenge of collaboration in math and engineering, Proceedings of IEEE/ASEE Frontiers in Education 2001 (pp. 23-28). Reno, NV: IEEE.

Hudson, J. M., \& Bruckman, A. (2002). IRC Français: The creation of an Internet-based SLA community. Computer Assisted Language Learning, 15(2), 109-134.

Joinson, A. (1998). Causes and implications of disinhibited behavior on the Internet. In J. Gackenbach (Ed.), Psychology and the Internet: Intrapersonal, interpersonal, and transpersonal implications (pp. 43-60). San Diego, CA: Academic.

Kelm, O. R. (1992). The use of synchronous computer networks in second language instruction: A preliminary report. Foreign Language Annals, 25(5), 441-454.

Kern, R. G. (1995). Restructuring classroom interaction with networked computers: Effects on quantity and characteristics of language production. Modern Language Journal, 79(4), 457-476.

Kolodner, J. L. (1997). Educational implications of analogy: A view from case-based reasoning. American Psychologist, 52(1), 57-66.

Krashen, S. D. (1985). The input hypothesis: Issues and implications. New York: Longman.

Latané, B. (1970). Field studies in altruistic compliance. Representative Research in Social Psychology, 1(1), 49-61.

Latané, B., \& Darley, J. M. (1968). Group inhibition of bystander intervention in emergencies. Journal of Personality and Social Psychology, 10(3), 215-221.

Latané, B., \& Darley, J. M. (1969). Bystander “apathy.” American Scientist, 57, 244-268.

Latané, B., \& Darley, J. M. (1970). The unresponsive bystander: Why doesn't he help? New York: Appleton-Century-Crofts.

Latané, B., \& Rodin, J. (1969). A lady in distress: Inhibiting effects of friends and strangers on bystander intervention. Journal of Experimental Social Psychology, 5, 189-202.

Lave, J., \& Wenger, E. (1991). Situated learning: Legitimate peripheral participation. Cambridge, England: Cambridge University Press.

Matheson, K., \& Zanna, M. P. (1988). The impact of computer-mediated communication on self-awareness. Computers in Human Behavior, 4(3), 221-233.

Newman, D., Griffin, P., \& Cole, M. (1989). The construction zone: Working for cognitive change in school. New York: Cambridge University Press.

Ong, W. J. (1982). Orality and lLiteracy: The technologizing of the word. New York: Routledge.

Ortega, L. (1997). Processes and outcomes in networked classroom interaction: Defining the research agenda for L2 computer-assisted classroom discussion. Language Learning and Technology, 1(1), 82-93.

Palonen, T., \& Hakkarainen, K. (2000). Patterns of interaction in computer-supported learning: A social network analysis, Fourth International Conference of the Learning Sciences (ICLS) 2000 (pp. 334-339). Ann Arbor, MI: Lawrence Erlbaum Associates, Inc..

Payne, J. S., \& Whitney, P. J. (2002). Developing L2 oral proficiency through synchronous CMC: Output, working memory, and interlanguage development. CALICO Journal, 20(1). 
Rick, J., Guzdial, M., Carroll, K., Holloway-Attaway, L., \& Walker, B. (2002). Collaborative learning at low cost: CoWeb use in English composition, Proceedings of Computer Supported Collaborative Learning (CSCL) 2002 (pp. 435-442). Boulder, CO: Lawrence Erlbaum Associates, Inc.

Riel, M. (1996). Cross-classroom collaboration: Communication and education. In T. Koschmann (Ed.), CSCL: Theory and practice of an emerging paradigm (pp. 187-208). Mahwah, NJ: Lawrence Erlbaum Associates, Inc.

Rogoff, B. (1994). Developing understanding of the idea of communities of learners. Mind, Culture, and Activity, 1(4), 209-229.

Rosenthal, A. M. (1964/1999). Thirty-eight witnesses: The Kitty Genovese case. Berkeley, CA: University of California Press.

Scardamalia, M., \& Bereiter, C. (1991). Higher levels of agency for children in knowledge building: A challenge for the design of new knowledge media. Journal of the Learning Sciences, 1(1), 37-68.

Schön, D. A. (1987). Educating the reflective practitioner. San Francisco: Jossey-Bass.

Schumann, J. H., Holroyd, J., Campbell, R. N., \& Ward, F. A. (1978). Improvement of foreign language pronunciation under hypnosis. Language Learning, 28(1), 143-148.

Soloway, E., Guzdial, M., \& Hay, K. E. (1994). Learner-centered design: The challenge for HCI in the 21 st century. Interactions, $1(2), 36-48$.

Songer, N. (1996). Exploring learning opportunities in coordinated network-enhanced classrooms: A case of kids as global scientists. Journal of the Learning Sciences, 5(4), 297-327.

Spears, R., Lea, M., \& Postmes, T. (2001). Social psychological theories of computer-mediated communication: Social pain or social gain? In W. P. Robinson \& H. Giles (Eds.), The new handbook of language and social psychology (2nd ed.), (pp. 601-624). New York: Wiley.

Sproull, L., \& Kiesler, S. (1991). Connections: New ways of working in the networked organization. Cambridge, MA: MIT Press.

Wang, X., \& Hurst, R. (1997). An empirical study of computer-assisted class discussion: Effects on social interaction and group dynamics, Proceedings of the Third International Conference on Foreign Language Education and Technology (pp. 431-448). Victoria, Canada: University of Victoria Language Centre.

Weisband, S. (1992). Group discussion and first advocacy effects In computer-mediated and face-to-face decision making groups. Organizational Behavior and Human Decision Processes, 53(3), 352-380.

Wertsch, J. V. (1985). Vygotsky and the social formation of mind. Cambridge, MA: Harvard University Press.

Zajonc, R. B. (1965). Social facilitation. Science, 149(3681), 269-274. 